\title{
SOMOS. LA ESCRITURA A CONTRAPELO DE LA HISTORIA DEL FRENTE DE LIBERACIÓN HOMOSEXUAL (1973-1976)
}

\author{
SIMONETTO, Patricio \\ (UNQ/CEHCME)
}

\section{Resumen:}

Enmarcado en un proyecto de investigación que se propone la reconstrucción de la historia del Frente de Liberación Homosexual (1967 - 1976), el siguiente trabajo analiza la publicación escrita de dicha organización, la revista "Somos". La misma contó con 8 números, cada uno de los cuales, alcanzó una tirada de aproximada de 500 ejemplares. En esta se combinaban artículos literarios, denuncias a los edictos policiales, notas internacionales, cartas de otros movimientos, dibujos, testimonios de la vida homosexual y ensayos teóricos, por lo cual, este corpus se vuelve una fuente innegable para quienes intentan dilucidar elementos sobre las relaciones de Género en el periodo reseñado en nuestro país.

\section{Palabras clave:}

Revista "Somos" - Frente de Liberación Homosexual - Género

\begin{abstract}
:
Framed in a research project that the reconstruction of the history of the Gay Liberation Front (1967 - 1976) proposed the following paper analyzes the organization written notice of such publication, the magazine "We". The same 8 numbers and counted with a circulation of about 500 copies per issue. In this literary articles, complaints to the police edicts, international notes, letters from other movements, drawings, testimonials of gay life and theoretical essays were combined, so this corpus becomes an undeniable source for those trying to elucidate elements on Gender relations in the reporting period in our country.
\end{abstract}

\section{Keywords:}

"Somos" Magazine - Homosexual Liberation Front - Gender 


\section{SOMOS. LA ESCRITURA A CONTRAPELO DE LA HISTORIA DEL FRENTE DE LIBERACIÓN HOMOSEXUAL (1973-1976)}

\section{PATRICIO SIMONETTO (UNQ/CEHCME)}

Este trabajo se propone analizar la publicación Somos, expresión pública del Frente de Liberación Homosexual de la Argentina (FLH) entre los años 1973-1976. Dicha organización actuó en la esfera pública entre los años 1967-1976 y en su seno confluyeron organizaciones de distintas tendencias políticas que buscaron constituirse como un núcleo que estableciera un nexo entre la emancipación social y la "liberación" sexual.

Para llevar a cabo el objetivo propuesto se analizaron los 8 números de la publicación, todos ellos aportados junto a otros documentos por la Comunidad Homosexual Argentina (CHA). Aunque la revista contó con una corta vida, de tan solo tres años, y tuvo una periodicidad irregular, constituye un aporte documental para la reconstrucción de la constelación crítica del FLH. El corpus seleccionado nos presenta una potencial vía de acercamiento a las elaboraciones teóricas de la organización, como así también una cronología de su acción. Lo cual no implica una lectura cerrada del escrito en sí misma, es decir, no propone un hermetismo textualista. Por el contrario, se analizan los escritos en relación con los flujos históricos, políticos, sociales y culturales que lo atraviesan. En decir, sus condiciones sociales de enunciación. De lo que se trata no es solo de pensar lo dicho, sino también en qué situación se lo dijo, quién lo dijo y qué hace con ello quién se lo apropia.

El análisis de Somos, nos permite decodificar entre otras cosas, el modo en que el FLH constituyó su intervención y su presentación en sociedad. En otras palabras, el modo en que la organización codificó su identidad público-política. A su vez, nos brinda la posibilidad de dar cuenta de sus distintos campos de acción, de las disputas con sus adversarios y de las relaciones políticas nacionales e internacionales que fueron constitutivas de su proyecto. Así también, de modo lateral, nos acerca a las distintas complejidades identitarias que interpelaban a aquel sujeto nominado "homosexual" en el periodo señalado. En suma, nos proponemos entender la agenda que la revista Somos intentaba constituir, difundir y efectuar, en relación a su contexto y a las respuestas particulares que implicaban una publicación que con una fuerte impronta política se conformó anclada en la temática de la disidencia sexual, lo cual le otorgaría rasgos pioneros para la época.

Partimos de la base de que toda construcción de una narrativa del pasado adquiere significación en relación con un "ahora". Si somos capaces de señalar, como tentativa, que dicha publicación fue una de las primeras en abarcar a la homosexualidad y a la política como temática en la región, quizás responsable de iniciar el camino de las actuales publicaciones referenciadas en el campo,: ¿no es factible extender un punto de unión reflexiva entre Somos y la actual Soy (que dentro de las numerosas publicaciones de consumo dentro de la comunidad de Lesbianas, Gays, Travestis, Transexuales y Bisexuales (LGTTB), es referenciado por ser suplemento del diario masivo Pagina 12)? ¿Cuál es la relación que existe al constituir sus nombres como conjugaciones afirmativas del verbo ser?

El suplemento Soy tiene como punto de contacto con Somos el abarcar la temática señalada desde una perspectiva política. A pesar de esto ¿Qué expresa el paso de la auto nominación Somos a la 
singularización que implica Soy? $?^{1}$ ¿Qué transformaciones se corresponden con este cambio enunciativo? ¿Cuáles han sido los desplazamientos, las rupturas y las transformaciones ideológicas que habilitaron este cambio? ¿Qué ha sucedido en el paso de un boletín militante a la emergencia de los suplementos masivos de la temática? Todas estas preguntas, aunque no se proponen ser resueltas por el artículo, guían e inspiran muchas de las valoraciones de este trabajo y le otorgan sentido al carácter de la indagación.

\section{Género e historia}

La escritura histórica presupone una lectura a contra pelo, es decir, no implica relatarla "como verdaderamente ha sido"; sino recuperarla a contra luz, con sus matices, trayendo al presente a los que han quedado en el silencio. Este método, aportado por la perspectiva de Walter Benjamin (2007), permite traslucir las complejidades de la dinámica histórica. Por consiguiente, si la constelación que nos proponemos recuperar parece haber quedado bajo las ruinas del golpe de Estado de 1976, es necesario hacerlo en una doble relectura. No implica solo recobrar el sentido de quienes cayeron tras la derrota política de la década señalada sino, también, la de iluminar a quienes permanecen silenciados en el propio campo de los vencidos. Es decir, revitalizar los lazos históricos y los procesos de sectores acallados o con voces tenues, que dentro de los trabajos que también presuponen una recuperación histórica de los legados militantes-políticos, quedan obturados o sesgados por los dispositivos sexuales-morales que aún operan sobre la narrativa histórica.

De este modo, la labor propuesta pretende dar cuenta de legados biográficos colectivos, de formas de vida a contramano de las formas hegemónicas. Este elemento señalado ha sido en gran medida nutrido por los estudios de género que se han preguntado, por ejemplo, por el lugar de la mujer en las organizaciones militantes armadas (Diana, 1996; Sepúlveda, 2013; Peller, 2012; Oberti, 2013), el desarrollo del feminismo en la décadas del 60’y 70’ (Trebisacce, 2010, 2013; Gramático, 2007) las relaciones de género en la década del 60’ desde una mirada transversal de las industrias culturales, las organizaciones políticas y las relaciones familiares (Cose, Fellitti y Manzano, 2012), entre otros.

Existen pocos trabajos que han abordado el análisis de la revista Somos. En particular el de Joaquin Insausti (2007) aporta una descripción del proceso de conformación y disolución del FLH, tramando los procesos contextuales en los que se inscribe la escritura de la revista. A pesar de dar cuenta del itinerario militante y del trasfondo político y social en los que se articula Somos, deja vacante el análisis de las distintas dimensiones (contenido, estética, circulación, etc.) de la publicación. En suma, aunque otorga densidad histórica al proceso de codificación de la publicación en términos analíticos, deja zonas por abordar que pueden retroalimentar dicha narración. Por otro lado, el trabajo de Bárbara Bilbao (2012) reconstruye la militancia del FLH desde sus prácticas comunicacionales y, con otra metodología, la investigación de Fernando Rada Schultze (2012) busca delinear las estrategias de acción política de los primeros movimientos homosexuales a través de entrevistas actuales a miembros del Grupo Nuestro Mundo (GNM). Vespucci Guido (2011) aportó un análisis discursivo de los usos de conceptos como sexualidad, familia y liberación en algunos materiales del frente.

Por último, aparecen referencias a Somos en el trabajo autobiográfico y ensayístico de Néstor Perlongher (2008), quien tras hacer un balance político de la experiencia del FLH, valora el carácter de la publicación como documento histórico. También, el trabajo de José Sebrelli aportó una fuente memorial para analizar la historia de la organización. Su participación en Triángulo

\footnotetext{
${ }^{1}$ El suplemento Soy apareció el 28 de marzo del 2008. En su primer número la periodista Maria Moreno publicó un artículo titulado "Una lengua política" donde anunciaba que el nuevo proyecto impulsado por el diario ubicaba su referencia en la tradición de Néstor Perlongher, referente del FLH y uno de los principales exponentes de Somos.
} 
Rosa, grupo activo dentro del FLH que tomó su nombre de la insignia con la que los nazis obligaban a los homosexuales a identificarse en campos de concentración, llegó a su fin cuando el colectivo inició un dialogo con el peronismo.

El FLH y, por ende, la publicación Somos, se corresponden con un proceso de emergencia social y política donde los "nuevos significados y valores, las nuevas prácticas, las nuevas relaciones y tipos de relaciones, son creadas en continuo" (Williams, 2009). Es en este contexto que se inserta nuestro análisis de la publicación. Desde el año 1955, con la proscripción del peronismo, el movimiento obrero y los sectores populares comienzan a tejer alianzas y aumentan la radicalidad de sus medidas en oposición al gobierno. A partir del año 1966, la llamada "Revolución Argentina”, gobierno dictatorial liderado por Juan Carlos Onganía, impuso un fuerte cambio en las políticas de Estado. Por medio del intervencionismo, se propuso beneficiar a sectores del capital concentrado en detrimento de los asalariados, como a su vez atacar las tradiciones de la organización sindical, valiéndose de la fragmentación y la cooptación. Estas políticas se dieron en el marco de un proceso que, intrincado en disputas dentro de las clases dominantes por establecer un patrón de acumulación de capital, produjo la alternancia entre gobiernos civiles y militares y abrió una brecha donde se formaron e intervinieron sectores de la izquierda radical (Schneider, 2005, 2013).

Entre estas formas de organización aparece el precedente del FLH, el Grupo Nuestro Mundo (1967). En este corto período comienzan a extenderse y organizarse las fuerzas sociales que darían lugar al estallido del Cordobazo (1969). A lo largo de los tres años siguientes, este método explosivo se profundiza. Desde diferentes partes del país los llamados azos, convocan a estudiantes y trabajadores a enfrentar al régimen (Izaguirre, 2012). Mientras tanto, en el interior de los sindicatos, el apoyo inicial al gobierno de Onganía devendría luego en un paso obligado a la oposición ante la prohibición de los convenios colectivos de trabajo y la intervención política de los gremios. Estos giros abruptos fomentaron las fracturas y las crisis de legitimidad de dichas conducciones, permitiendo así el surgimiento de nuevos fenómenos de base como el Clasismo, tendencia al interior del movimiento obrero que tenía como horizonte la independencia política de los trabajadores tanto de la burocracia sindical como de los gobiernos "burgueses" e intentaron establecer nexos entre lo sindical y lo político en la perspectiva de la transformación social radical (James, 2003).

A su vez, la fundación de la revista en 1973 se corresponde con el periodo de consolidación del FLH y su intento de masificación por vía de la inserción en el ala izquierda del peronismo. En términos de una semiótica social, supone el intento de inclusión dentro del dispositivo discursivo peronista, que involucraba la articulación de un "nosotros" donde se asociaban las figuras de Perón, nación, verdad, justicia social y liberación, contrapuesto a un bloque de "ellos" vinculados a las fuerzas imperialistas en el país, la oligarquía y el capital transnacional concentrado (Verón y Sigal, 2010). El dispositivo peronista implicaba una trama compleja, en tanto las relaciones de legitimidad que le asignaban un carácter de verdad a su "nosotros" comprendían un conjunto de dispositivos ético-morales que rechazaban todo intento de inserción por parte del FLH. En efecto, desde el primer gobierno peronista, esta identificación estaba asociada con la ponderación del rol familiar y sus roles prescriptivos de género, manteniendo una continuidad con las políticas familiaristas de los gobiernos previos, afirmando, de este modo, la imposición simbólica de rígidas normas sexuales. Por esto mismo apareció como parte de la otredad a combatir la figura de los "amorales", un sujeto considerado inferior y femenino. Dicha operación en el plano de los significantes sociales sería acompañada con una fuerte política represiva, denunciada desde las páginas de Somos (Acha y Ben, 2004), y por políticas sanitarias como, por ejemplo, la revisión del sistema abolicionista de la prostitución, vigente desde el año 1936, con la autorización excepcional de prostíbulos cercanos a los cuarteles militares por temor a los "desvíos" de las conductas sexuales de los jóvenes conscriptos (Biernat, 2007: 278-279). 
Los procesos sociales a nivel internacional colaboraron con la formación del clima socialintelectual referenciado. El Mayo Francés (1968) convulsionaría la cultura de izquierda. La crítica al sistema capitalista sería acompañada por un cuestionamiento a las pautas sexuales y culturales. Las revueltas culturales aportarían una revisión violenta a las costumbres y una disrupción contra las normalidades. Desde esta perspectiva, lo más cercano era digno de crítica, el aliado tenía que dejar de ser lo que era para que el cambio pudiese producirse (Casullo, 2007). De este modo, se insertó, en los horizontes simbólicos de algunos sectores de la izquierda, la crítica política y personal y se re codificaron las "tareas revolucionarias". En consecuencia, la toma del poder no sería la única vía de resolución, sino también el cuestionamiento constante a la trama social-moral dominante que atravesaba a cada uno de los sujetos. De este modo, estos movimientos pusieron como nuevo objetivo la liberación del deseo, en una correspondencia entre el freudismo y el marxismo.

Las transformaciones en los dispositivos culturales, la extensión de la cultura de consumo y la consolidación dentro del espacio público de los medios masivos de información transformaron profundamente las identidades y las representaciones sociales. Apareció en la escena la juventud, que asumió un papel central, tanto en el ámbito político como en la discursividad mediática. Junto a este nuevo actor, la sexualidad, la binariedad femenino-masculino, las revistas políticas, la literatura latinoamericana, entre otros elementos, reconfiguraron la vida cultural de masas (Pujol, 2003).

Estos procesos colaboraron con la transformación que vivieron las organizaciones homosexuales en Occidente. El punto de quiebre, que daría lugar a un nuevo episteme político de la cuestión sexual, sería la revuelta de Stonewall en Estados Unidos el 28 de junio de 1969. Ante las constantes redadas de la policía, cordones de jóvenes homosexuales, en su mayoría negros y latinos, se reunieron en las esquinas de Nueva York al grito de "Gay Power". En pocas horas unos dos mil homosexuales rodeaban a cuatrocientos policías. Esta revuelta constituyó el mito fundacional de los movimientos homosexuales en Occidente. De este modo se tramó un relato que sintetizaba este cambio de perspectiva de las organizaciones militantes: la imagen de cientos de jóvenes marginados enfrentando a las fuerzas del orden, constituirían una identificación innegable para quienes en otros países sufrían las mismas prácticas represivas. Desde distintas latitudes del globo, las revueltas de trabajadores, estudiantes y sectores populares, ligarían sus condiciones precarias de vida a una cuestión sistémica. De este mismo modo, los movimientos homosexuales desarrollarían como respuesta a un sistema capitalista y patriarcal, un arsenal de posicionamientos y métodos radicales de acción y organización (Wilson, 2001).

En síntesis, el fundamento de este trabajo presupone entender el contrapunto histórico que dicha publicación y organización significaban al itinerario e imaginario militante de la época. Estableciendo una analogía con el trabajo de Eduardo Grüner (2010) sobre la revolución en Haití, la emergencia de procesos de visibilidad y organización de colectivos homosexuales radicales, como así también de feministas, puso en crisis las pretensiones del universal abstracto de los proyectos de emancipación política setentistas, poniendo en cuestión su carácter uniforme y cerrado. En efecto, estas experiencias mostraron sombras, contradicciones, y complejidades de las que es preciso dar cuenta. El hecho de que el FLH debiera su fundación a la expulsión de un grupo de militantes del Partido Comunista (PC) que habían sido rechazados, a su vez, de distintos campos de acción política como el peronismo y el Partido Socialista de los Trabajadores (PST), presupone comprender las complejidades multidireccionales de la dinámica histórica. Las nuevas formas de organización pusieron a la luz los puntos de contacto y distancias entre el imaginario discursivo y la dinámica histórica real. De este modo, permiten pensar las complejas condiciones morales "burguesas" que los grupos subalternos decían rechazar y que, de todos modos, operaban sobre su práctica política.

La lectura de los números de la revista Somos nos permite, entonces, trazar un mapa de las relaciones que implicaron al colectivo FLH. El periodo señalado (1973-1976) presenta el 
momento de organización de mayor densidad histórica, de reconfiguraciones, de presencia numérica y de producción teórica. Es decir que este análisis nos abre una puerta al conjunto de intersecciones políticas, identitarias y relacionales del FLH.

\section{Una publicación de género}

La revista Somos puede ser considerada como una publicación de estrecha relación con la actividad política y la(s) posición(es) ideológica(s) del FLH. Estas posiciones no presentaban un todo homogéneo, por su propia característica de frente donde coexistían más de diez organizaciones con diversidad estratégico-política y con miradas difusas ancladas en posiciones de izquierda anticapitalista, anti imperialista y anti patriarcales. Somos se presentaba a sí misma como "un instrumento de lucha" en función de que cada artículo estaba hecho con la finalidad de ayudar "al proceso de concientización y liberación de los homosexuales y de todos los oprimidos" (Somos, 1974, No4). Por otro lado, se trataba de un foro abierto. Es decir que los artículos no representaban exactamente la opinión de sus redactores, lo cual se explicitaba en cada uno de sus números ¿Cuál era el sentido de aquella polifonía? La revista Somos presentaría para este colectivo de homosexuales la posibilidad no solo de difundir su propia organización sino también de potenciar las voces acalladas, marginadas y segregadas y, así, darles visibilidad en el mundo de la comunidad homosexual y militante.

El único antecedente de la publicación, con unos meses de anticipación, fue el periódico Homosexuales. El mismo fue disuelto tras importantes debates en torno a un artículo titulado "Machismo y Opresión Sexual", donde se afirmaba que la posición femenina dentro de algunos homosexuales era la otra cara del machismo, generando incomodidad, desacuerdos y disparidades dentro del movimiento. Aquel periódico tuvo una circulación restringida, podríamos afirmar que casi nula (Perlongher, 2008: 81).

Luego devino la segunda experiencia: la revista Somos. La misma contaba con una tirada aproximada de 500 ejemplares por número que circulaban a nivel nacional y, a su vez, se enviaban otros números a Brasil, Uruguay, Perú, México, Estados Unidos, Canadá, Francia, España, Italia, Reino Unido, Alemania (occidental), Suiza, Cuba, Austria, Holanda y Puerto Rico (Somos, 1974, No 4). Esta profusa circulación muestra la amplia gama de contactos internacionales que llegó a tener el FLH, al punto tal que en momentos donde aumentaron las condiciones represivas en el país, recibirían su correo en una dirección de Nueva York.

El carácter técnico nos permite pensar no solo las relaciones de producción interna, sino también la relación entre su productor y el receptor, como así también las relaciones estéticas y el sistema de circulación (Eagleton, 2013). La revista utilizaba la foto duplicación, tomando las características propias del fan₹ine, métodos estéticos popularizados a partir de la década del 60', que consistían en el dibujo a mano, el recorte y la duplicación masiva.

Somos tuvo puntos de contacto con otros proyectos desarrollados en Argentina y en Latinoamérica que dan cuenta de que la publicación era sintomática de un fenómeno subterráneo que iniciaba su proceso de emergencia. Muchos de ellos se desarrollaron como prácticas de desobediencia sexual, como estrategias poético-políticas mediante las cuales se problematizaron los ordenamientos de saber/poder del régimen mayoritario heterosexual. Ya en las décadas del '50 y '60 se establecieron las primeras redes de bares homosexuales en la región, espacios de encuentro y de sociabilización, donde muchos de estos proyectos encontraron su origen. Es decir, que podríamos afirmar que esta publicación se corresponde con el proceso de gestación de formaciones político-culturales que se movieron en distintos espacios e instituciones, formales o no, pero que compartieron ciertos puntos de contacto (Williams, 2009).

En nuestro país, contra la política cultural represiva iniciada por el gobierno de facto de Juan Carlos Onganía (1966-1970), se gestaron formaciones culturales radicales, agrupadas en el 68' 
Argentino, que tendieron a ligarse al movimiento obrero y que dieron cuenta de las transformaciones en el clima artístico e intelectual del país (Longoni y Mestman, 2010). En el Centro de Experimentación Audiovisual Di Tella, el artista plástico vanguardista Alfredo Rodríguez Arias presentaría una gigantesca imagen de Freud y llamaría, en clave humorística, a fomentar la formación de un movimiento freudo-guevarista por la libertad sexual y social, revalorizando la figura del psicoanálisis como aquella que puso la figura del deseo en cuestión. Otra experiencia sintomática se expresaría en la obra del artista plástico Roberto Plate, la misma consistía en la instalación de un baño público donde en el resguardo de la intimidad, la gente podría hacer un descargo emocional. En el baño aparecieron graffitis contra el gobierno. Denunciados por afectar la moralidad pública, la policía decidió clausurar el espacio. El artista tomó la barra de clausura y la presencia de la policía impidiendo el ingreso de los concurrentes como parte del espectáculo. Este icono, el del baño público, como señalaré a lo largo del trabajo, es una figura central en la vida social homosexual.

En simultáneo con la publicación analizada, el artista conceptual colombiano Miguel Ángel Rojas, desarrolló un nuevo tipo de teatro testimonial de la vida homosexual. Asimismo, y en una suerte de actitud voyeurista, se propuso visibilizar la actividad homosexual en los baños públicos. Espacio de referencia, también, para Somos que anunció en un poema: "los baños públicos son nuestros salones de fiesta" (Somos, 1973, No 3). Por su parte, en 1972 Alvaro Barrios, uno de los primeros artistas conceptuales de Colombia, se apropió de imágenes populares homo eróticas en sus grabados y, en 1975, Carlos Leppe, artista vanguardista del grupo Escena de Avanzada, hacía instalaciones donde ponía el cuerpo como construcción social en tensión con un sistema de secuencias gráficas (AA.VV, 2013). Muchas de estas experiencias se extendieron y visibilizaron en la década del ' 80 .

\section{Análisis y contenidos.}

Si estableciésemos un mapeo temático, podríamos afirmar que del conjunto de textos e imágenes que componen a Somos: el 19,12\% refiere a notas de producción teórica, el 16,58\% a relatos li-

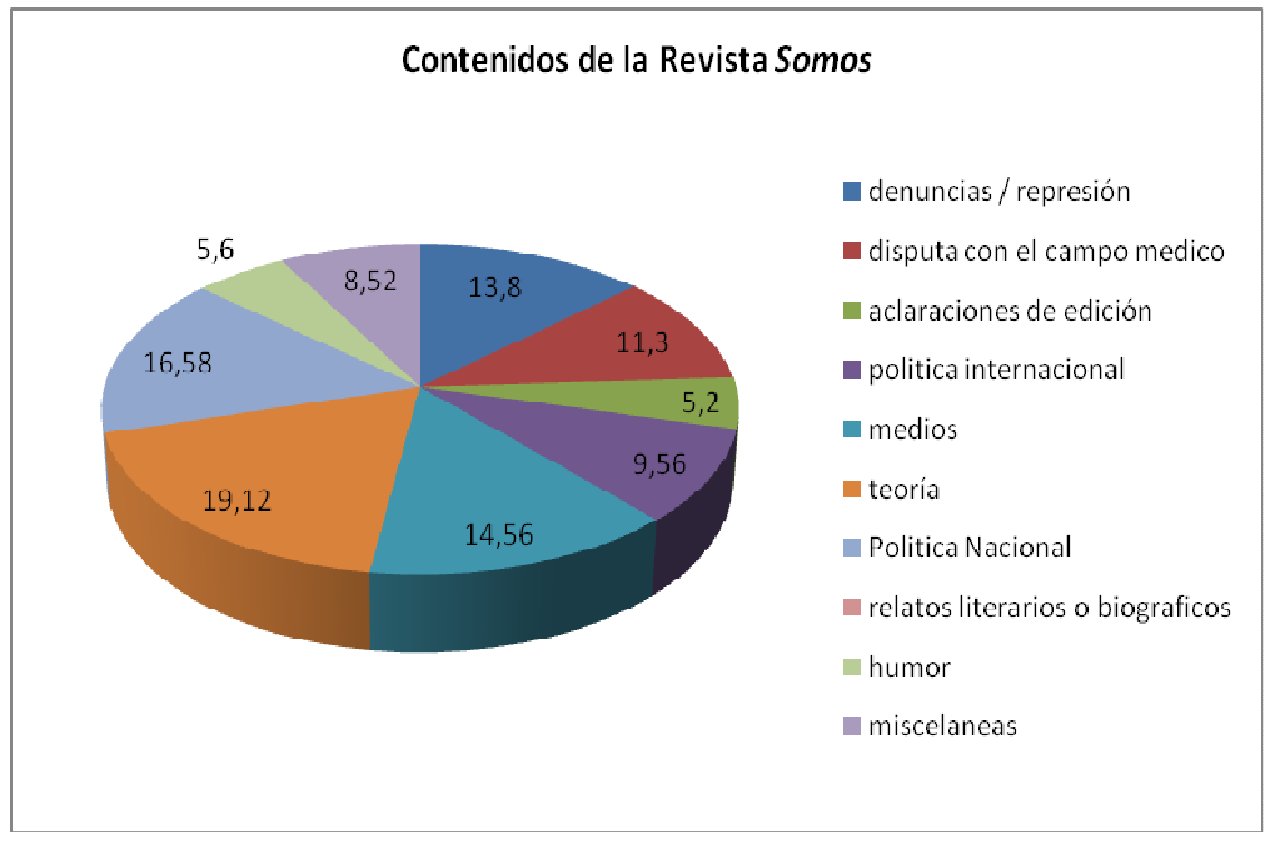

Elaboración propia en base a 8 números de Somos aportados por la CHA. 
terarios o testimonios de homosexuales, el 16,58\% a comunicados o procesos políticos nacionales, $14,6 \%$ a la reproducción de notas inferidas en otros medios, el 13,8\% a denuncias o discusiones sobre la represión estatal de la vida homosexual, el 11,3\% a las disputa con los campos de saber referidos a la salud, el $9,56 \%$ a la sección de política internacional, el 5,60\% al humor, el 5,2\% son aclaraciones de la edición y el 8,52\% tapas o artículos variados que no tienen una clasificación común.

Entendiendo que, a pesar de su carácter abierto como foro polifónico, la revista contiene una orientación editorial, una edición, filtro y organización de su contenido, se puede destacar el carácter fragmentario de las temáticas abordadas, que cambian su composición según el número. Aunque existe un diálogo con la agenda pública del momento, se ve en sus contenidos una apuesta a fundar y exponer una agenda propia o, visto de otro modo, que las preocupaciones que incumbían al público homosexual no eran preocupación de la agenda pública mayoritaria. Estas temáticas esbozan los puntos nodales de la vida política de la organización y sus preocupaciones identitarias.

En primera instancia, la referencia a la represión estatal configura un espacio importante en la revista, que no solo está presente en los artículos centrados específicamente al respecto, algunos teóricos y otros a modo de ejemplo, sino que también se ve en las notas tomadas de diarios. Todos ellos prefiguran las dificultades que los homosexuales tenían a la hora de realizar y expresar sus formas de vida en la esfera pública. En el primer número presenta a sus lectores la "Cartilla de Seguridad", en la misma se especificaban cuestiones legales de los edictos policiales que, legislados a partir de 1930, eran utilizados por la policía en actividades persecutorias. En consecuencia, propone métodos para evitarlos, derechos civiles que deben ser cumplidos y modos de acción en caso de ser detenidos. En ese mismo número lanza un comunicado, "La tía Margarita impone la moda Cary Grant", donde hace público su rechazo a las acciones de Luis Margaride, jefe de alto mando de la policía local reconocido por sus razias públicas pro moral contra homosexuales y heterosexuales (Somos, 1973, No1). En otro de los ejemplares, anuncia la colecta de fin de año, para aquellos que pasarían presos las fiestas en el pabellón especial de Devoto (Somos, 1973, N³). Los ejes de su denuncia irán variando. El tercer mandato peronista fue acusado por Somos por la creciente represión que se habría ejercido desde el Estado y por la medida que suprimió el uso de los métodos anticonceptivos (1975). También se recusaron las acciones paraestatales llevadas adelante por la Asociación Anticomunista Argentina (AAA), ligada a la acción política de sectores asociados al ministro de Bienestar Social del gobierno peronista, José López Rega.

Este conjunto de operaciones sobre la dimensión pública de la vida, se encuentra también inferido en los relatos literarios y testimonios de vida de homosexuales que eran exhibidos en la revista. La vida privada, los encuentros casuales, los circuitos clandestinos de circulación son figuras comunes en la narrativa de Somos. La circulación de una vida marcada por la figura del "flâneur homosexual", como aquél que transita la ciudad en busca de un encuentro, que circula el espacio en contactos secretos, que analiza todo por un juego de miradas (Acha y Ben, 2004). Así, distintos relatos abarcan el asesinato de un homosexual en manos de dos "chongos" (Somos, 1974, $\mathrm{N}^{\circ} 5$ ), la descripción de un joven y su relación posesiva con un hombre que lo reducía a una figura débil, endeble (Somos, 1974, Nº) y el asedio de una fiesta por parte de la policía (Somos, 1974, $\left.\mathrm{N}^{\mathrm{o}} 5\right)^{2}$

\footnotetext{
2 Un relato y análisis de las crónicas policiales que en los setenta relataron el asesinato de "amorales" y sus implicancias en la producción de subjetividades y la valoraciones de género puede preciarse en el trabajo se Santiago Insausti (2012). En el mismo, el análisis de 57 crónicas de diarios porteños, donde ubico un patrón común: "El relato es siempre muy similar: un amoral encuentra a un hombre en la calle $y$, generalmente con una promesa dineraria de por medio, ambos concurren al domicilio del primero, donde luego de tener sexo, el hombre roba, golpea y ultima al homosexual antes de huir. Periodistas, policías y jueces, investigando posteriormente el hecho, coinciden por lo
} 
Quizás el aspecto crucial de estos relatos sea su capacidad disruptiva, su intento de reposición de la imagen. En varias notas se hace alusión al tratamiento mediático, a la aparición metonímica de la figura de "amoral". La producción unívoca de un signo que obtura y legitima, la trama de prácticas opresivas. Dicho signo sería objeto de disputa por parte del FLH. Los espacios de codificación de saber/poder, de categorización, de ordenamiento en el imaginario simbólico constituyen parte de las temáticas centrales de la revista y la acción política de la organización.

Punto de disputa, aún en mayor medida que los medios, era para la revista el campo del saber médico. La relación y tensión con estos sectores atraviesa la codificación misma de la figura de la homosexualidad y se corresponde con las complejas relaciones entre género y ciencia, intrínsecamente ligadas en la historia social. El desarrollo de la Medicina, la Psiquiatría y la Psicología como disciplinas autónomas y la constitución de determinadas relaciones de fuerza, le brindan a éstas la capacidad de nominar a toda una serie de placeres no reproductivos masculinos como enfermedades morales (Ben, 1997). En Argentina, el proceso de constitución del Estado fue acompañado de la codificación de un sujeto moral racional colectivo contrapuesto a figuras negativas, consideradas "enfermas" para el cuerpo social. Con las políticas higienistas, como elemento fundamental en las políticas "civilizatorias", se codificaron una serie de intervenciones, de tecnologías políticas y de saberes especializados que tendieron a marginar a los sujetos considerados "enfermos" (Vezetti, 1985).

Más tarde, desde las culturas biomédicas y los medios masivos de comunicación se construyó un sentido público, una valoración del signo correspondiente al "homosexual". Es importante destacar que la carga significante de un signo se define en la intersección de intereses sociales dentro de los límites de un mismo colectivo semiótico y que como tal, es subproducto de las relaciones de fuerza y las disputas entre grupos sociales y clases, en las cuales se precisa su acentuación, su anclaje en su polisemia (Voloshinov, 2009). La homosexualidad, en su contenido significante se constituye en estas tensiones, entre un conjunto de normas sociales, relaciones establecidas entre el Estado, el campo médico, las figuras sociales dominantes, como así también las tracciones entre las distintas facciones dentro de las clases subalternas y las dominantes. La disputa por el sentido público, por la reapropiación de ciertos conceptos, por readjudicarle a los insultos, a las injurias el valor significativo de una forma de vida asediada, es una de las grandes batallas entabladas por Somos. En una situación histórica donde la relación entre el valor simbólico se corresponde explícitamente con un alto grado de violencia física, la batalla por la producción de sentido aparece intrínsecamente ligada a la vida misma.

En la disputa de sentido con el campo médico, se daba cuenta de discusiones centrales para estas disciplinas. En uno de los artículos de la revista se reprodujo un resumen del informe Kinsey (1953), el cual afirmaba que la homosexualidad había sido practicada desde los albores de la historia humana (Somos, 1973, No1). En otra nota se festejó la proclamación de la American Psiquiatric Asociation (APA) de que la homosexualidad no constituía una perversión psíquica (Somos, 1973, No3). También se destacó la realización de un escrache público a una conferencia medica realizada en el Teatro San Martín de la ciudad de Buenos Aires, donde se hacía referencia a la homosexualidad como una desviación psíquica (Somos, 1973, N³). Por otro lado se afirmó que los médicos y los psiquiatras eran los "policías blancos del sistema" y se los llamó a desertar en su tarea de difamación y normalización (Somos, 1974, N4).

general en exculpar al homicida, sosteniendo que éste, luego de tener sexo con el occiso, se da cuenta de la magnitud de la aberración cometida y debe recurrir a la violencia para salvaguardar su dignidad y su hombría." 


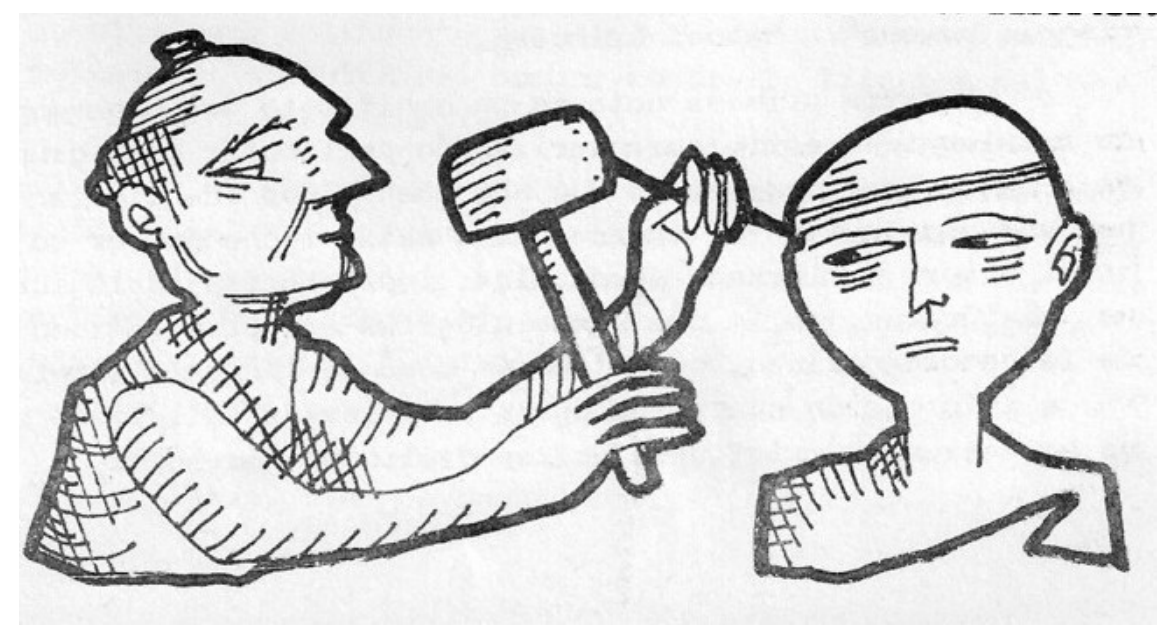

Imagen $\mathrm{N}^{0}$ 1. Somos, $\mathrm{N}^{\circ}$ 4, 1974. Caracterización del rol social del discurso biomédico.

En su dimensión teórica, la publicación dio cuenta de una serie de artículos y polémicas. Entre ellas, se brindan indicios sobre el Grupo de Política Sexual (GPS), espacio de confluencia entre miembros del FLH, movimientos feministas y varones heterosexuales. Se trataba de una usina intelectual que tenía como propósito el desarrollo teórico sobre la cuestión sexual y la revolución. Muchos de los artículos, tendrían punto de contacto con el manifiesto político del FLH: Sexo y Revolución (1973). Estos documentos, comprenderían una constelación ideológica que combinaba ideas propias del marxismo, del psicoanálisis y del feminismo. En estos textos se encuentran puntos de contacto con itinerarios de la teoría crítica. Entre ellos seguramente influenciaron los aportes del freudo-marxismo de Herbert Marcuse, filósofo popularizado después del Mayo Francés de 1968, y uno de los miembros de la escuela de Frankfurt que prestó más atención a la cuestión sexual (Marcuse, 1984). Una versión "críolla" de las teorías de la liberación del deseo, proponía disputar la representación de la revolución como un acto que no solamente debía trastocar las bases socioeconómicas de explotación al proletariado, sino que también, debía despojarse de las normas sexuales que consolidaban la reproducción de jerarquías sociales e imposibilitaban el pleno disfrute del cuerpo (Simonetto, 2014).

La dimensión política, propia de la prensa militante, entre los aspectos nacionales e internacionales, comprendió el nodo articulador de la constelación del FLH. En el plano internacional, se reprodujeron los comunicados de movimientos homosexuales símiles en distintas latitudes del globo, como así también de movimientos de inmigrantes (en el caso de EEUU). Estos lazos consistían en estipular una red relacional con otros grupos que compartían, por un lado, su posición marginal de exclusión, o de política centrada en la identidad y, por otro, su carácter autónomo, es decir, la incapacidad al igual que el FLH de insertarse en alguna tendencia política. Asimismo, se hicieron crónicas de participación de miembros del FLH en congresos internacionales temáticos u organizativos por los derechos civiles de los homosexuales. Es de destacar, también, la referencia a un encuentro con Andre Baudry, quien fue docente de filosofía, fundador del grupo homófilo Arcadie y su respectiva publicación, participó en Francia de importantes debates sobre la cuestión sexual y fue víctima de numerosas acusaciones y persecuciones por su tarea intelectual.

A nivel nacional, las expresiones políticas de Somos, conjugaron un conjunto de comunicados, acuerdos y declaraciones que nos indican la orientación política y los procesos de articulación del FLH. Si como señalamos, la publicación de la revista se condice con un giro organizativo, una tentativa de inserción en el dispositivo de enunciación peronista, esto queda comprobado en varios de sus artículos en los que se expresa un direccionamiento contradictorio y complejo. Al interior de la organización existían diferencias sobre la tarea que el FLH debía tomar ante el 
peronismo. Mientras que el GNM prefería delimitarse del movimiento peronista, según indicó su fundador Héctor Anabitarte en entrevistas recientes (Clarín, 09-02-2013, 03-03-2013), Néstor Perlongher y el grupo Eros buscaron mediante la participación en las gestas masivas de Plaza de Mayo (festejo de la asunción de Héctor Cámpora a la residencia en 1973) y de Ezeiza (retorno de Perón), insertarse dentro del campo peronista. Sospechamos que la segunda tendencia fue la predominante al interior de la organización.

A pesar de estas posiciones encontradas, la de algunos grupos que insistían en demarcarse del fenómeno peronista y la de otros de confluir en el seno del mismo, la mayoría coincidió en compartir el dolor por la muerte de Perón, "Consecuentes con nuestros postulados de unión y solidaridad con todos los sectores que luchan por derribar su opresión”. Sin embargo, Somos no dejó de denunciar "el grado de represión a la homosexualidad en un año de gobierno, expresada en razzias, detenciones arbitrarias y otras medidas coercitivas". Afirmaba que sin importar quienes sintieran o no el mismo dolor, se hermanaba con el pesar de los "oprimidos" y llamaba a estrechar filas junto al pueblo para llevar adelante la tarea de liberación, que implicaba en su discurso no solo un cambio estructural del país, sino también de cada uno de los actores de dicho proceso. Por último, indicaba la creciente violencia de la que eran víctimas las organizaciones políticas emergentes y la emparentaba con la violencia que día a día sufrían los homosexuales, lo cual señalaba el carácter coercitivo del sistema de dominación (Somos, 1974, Nº5).

Estas afirmaciones nos permiten deducir ciertos indicios, o confirmar hipótesis señaladas. Por un lado, el carácter polifónico de la publicación hacía coexistir en su seno posiciones diversas. De todos modos, Somos insistía en demostrar la pertenencia de los homosexuales dentro de la figura del "pueblo" como una minoría en disidencia. Por otro lado no solo denunció la violencia del régimen, estableciendo un nexo entre la violencia política y la identitaria, sino que también convocó a ligar el horizonte de la transformación radical de la estructura social a la transformación emprendida en la vida de cada uno de los sujetos. En el universo simbólico de los integrantes del FLH, y obturado por ciertas dimensiones en el práctico, la disputa contra las pautas morales dominantes se debía reñir tanto al enemigo como al aliado.

Las páginas de la revista se vieron abiertas, además, a las organizaciones feministas del país. Tanto el Movimiento de Liberación Femenina (MLF) como la Unión Feminista Argentina (UFA) encontraron en Somos un espacio de expresión. Al igual que en el Grupo de Política Sexual y en la Coordinadora Contra la Prohibición de Ventas de Anticonceptivos, el FLH, la UFA y el MLF coordinaron esfuerzos. Aunque con perspectivas, focos y una composición genérica distintas, estas organizaciones confluyeron en este horizonte simbólico, el de transformar lo personal en político, para cuestionar el conjunto de las pautas morales y éticas dominantes. Entre sus actividades se encontraron la difusión y el estudio de textos feministas prácticamente inexistentes en el país, que eran importados por la cineasta María Luisa Bermberg, los grupos de debate y discusión, la elaboración de documentos de análisis, el dictado de charlas debate, volanteadas en la calle, cuestionamientos públicos en charlas públicas de organizaciones de izquierda, cuerpos de profesionales, instando a cuestionar el lugar de las mujeres y los homosexuales en la sociedad (Simonetto, 2014).

Continuando con el método analítico con el cuál indagamos el conjunto del circuito de la producción, cabe preguntarse sobre los autores/productores. A saber: ¿Quiénes son los que escriben? ¿Qué nos dice esto al respecto? A modo de respuesta podemos decir que, a pesar de existir ciertas firmas de autoría: Bruno Frappat, Mabel, Maxo, Mab, Rodolfo Rivas, Rogelio Rivas, Francisco Blanco, Lopez de Vega, Federico de Arcilla, la mayoría de los artículos son anónimos. Si realmente queremos comprender las dimensiones sociales, simbólicas, ideológicas y culturales que atañen a esta publicación, de lo que se trata, haciendo extensiva la propuesta de Terry Eagleton (2013) es de "hacer hablar a los silencios". 
¿A qué se debe este anonimato? ¿Por qué, a su vez, las firmas son en gran parte seudónimos? Podemos ubicar en este signo ausente una doble realidad. Por un lado, las políticas represivas en sus variadas dimensiones, tanto la coerción estatal como la aplicación de los edictos policiales. Por otro lado el constante sometimiento por parte de la sociedad civil a la injuria, la discriminación y la violencia simbólica y física que condenaba a los integrantes del FLH a la vida anónima. La figura del baño público quizás resuma metafóricamente la incapacidad pública de expresión. La enunciación, sea por la vía que sea en lo público, como una condena que debería llevarse en privado. Había un conjunto de operaciones que tendían a la invisibilidad de estas prácticas sociales. Asimismo, la reivindicación de la firma colectiva (en su ausencia), se había vuelto una marca del FLH. Expresaba, para ellos, su política horizontal, anti referencial, contra los modelos monolíticos de construcción.

A pesar de esto, podemos pensar en la escritura cifrada de Nestor Perlongher, antropólogo y poeta, dirigente del FLH y quien fuese representante del Neobarroco Rioplatense (Wasem, 2008). También se citaban numerosos textos de autores reconocidos, entre ellos Bertolt Bretch, Jean Gennet, Jean Coctau, Alejandra Pizarnik, Kate Millet, Simone de Beauvoir, Jose Mario y Paul Valery. La referencia a escritores con influencia dentro del campo cultural, permitía a la revista poseer ciertos nombres con capital simbólico, le otorgaba a la misma cierta autoridad y, a su vez, traía a escritores que eran propios del consumo cultural de la izquierda, el feminismo y la comunidad homosexual.

Tomando este último indicio, es decir el de la referencia de autores propios de este grupo de consumidores, se nos abre una serie de preguntas de compleja resolución ¿Quiénes eran los receptores de Somos? ¿Cuál era la apropiación que hacían de la misma? Por ciertos indicios podemos imaginarnos que los receptores eran militantes de izquierda, homosexuales militantes o no y feministas. La cuestión de sus receptores era de interés para los autores de la revista. En dos ocasiones se esforzaron por realizar una encuesta en la que se recogían críticas, opiniones y temas a desarrollar (Somos, 1973-74, No3 y 4).

Por último, el formato de Somos se podría dividir en dos etapas que se corresponden con el desarrollo de la organización. El primer formato, asociado al fanzine, con ilustraciones a mano y foto duplicación, abarca los años 1973-1975 y se relaciona con el proceso de apogeo del FLH, con su intento de inserción en la política nacional. A partir del año 1975, el mismo pasó a ser un boletín mecanografiado. En su número 7 se indica: "Somos modifica, a partir de ahora, su modo de salir. Se editará manualmente en forma de boletín informativo, y semestralmente, como revista reflejando su producción teórico-cultural del liberacionismo homosexual. Agradecemos las colaboraciones y críticas" (Somos, 1975, Nº7). Lo cierto es que el formato de revista no volvió a existir, solo se difundieron dos boletines más: el $\mathrm{N}^{\mathrm{o}} 7$ y 8 .

¿A qué se debió este cambio de formato? Como lo anunciaron en estos últimos dos números, el creciente clima de represión y violencia que antecedieron al golpe comenzó a restringir la práctica militante de algunas organizaciones. En el caso del FLH, el enfrentamiento público con El Caudillo, periódico de derecha asociado a Lopez Rega, y la política persecutoria de la AAA. La creciente persecución, el miedo y el terror, los redujo rápidamente a un grupo de producción teórica. La presión represiva de la que eran víctima los homosexuales desde hacía años, creció en una escalada que se cristalizó en el Golpe de 1976. A lo largo de las páginas de estos boletines, se reprodujeron los comunicados de las distintas agresiones y represiones de la que fueron víctimas homosexuales y el conjunto de las organizaciones políticas.

\section{Estética: producción destructiva del sentido.}

En el plano estético Somos combinó el uso de ciertas características discursivas, escritas y visuales. Las imágenes, por lo que se deduce en las firmas, fueron en su mayoría dibujadas por algún sujeto 
cuyo seudónimo es Maxo. La revista se compone por un conjunto de dibujos que realzan la figura estética masculina y la femenina; se utiliza en variadas ocasiones la imagen de la mariposa, una de ellas enfrentando a un águila que representaría a EE.UU. Se resaltan dibujos de orangutanes o seres toscos asociados con la violencia policial y la figura de la represión también aparece mancomunada a aves enjauladas. En un afiche público de la organización esta imagen era asociada con el lema: "Los homosexuales luchamos por nuestro derecho a vivir en Libertad" (Somos, 1975, Nº).

Como destacamos en la figura de Perlongher, la escritura de Somos presentaba tácticas, elementos y recursos propios del neobarroco latino. Aunque esta tipificación pueda parecer arbitraria, sirve para comprender el método de producción de sentido de la revista, una suerte de semiosis barroca, tanto en la escritura como en las imágenes. Se podría destacar en común "que dan cuenta de un estado de crisis de los regímenes de producción discursiva”. Según Gilles Deleuze, una propuesta como "el escenario de una mutación o la práctica de una alteridad radical, que excede los límites de lo pensable". Se presenta un arte desde los márgenes, "que promueve inestabilidades y erosiona las fijezas, producto de la puesta en escena de la heterogeneidad" (Wasem, 2007: 23-54).

En sus tácticas persiste la utilización de la alegoría, unidades disruptivas que por vía de la cosificación de elementos naturales muestran su inevitable decadencia y la corrupción de las ideas que expresan (Benjamin, 2012). En términos de Ariadne Díaz (2009), una parálisis de la historia que busca destruir el carácter fetichista de los objetos y la vida misma, donde se busca escapar a la novedad mostrándola como siempre igual. En este mismo sentido, es que encuentro en su método poético, una suerte de valorización del shock, o la utilización del mismo en su producción. En un mundo fragmentario, fantasmagórico y fetichista, la utilización de este recurso en las técnicas artísticas permite interpelar al receptor. Desnaturalizando ciertos elementos y destruyendo lo ya dado, se construye un nuevo sentido, una nueva perspectiva (Eagleton, 2013).

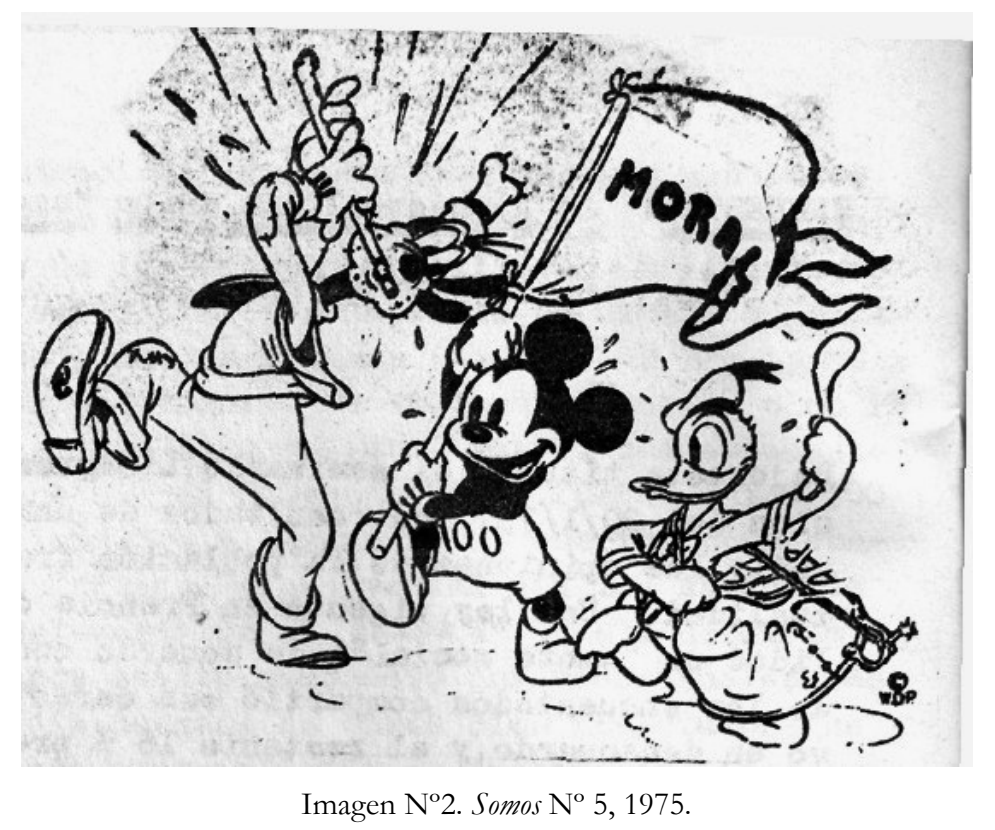

Como señalamos con anterioridad, uno de los objetivos de Somos, era establecer un dialogo con una amplia gama de actores atravesados por la cultura de izquierda. Su propuesta política conectaba la revolución sexual con el imaginario de "liberación" política y social. Bajo el título “QQuiénes son los verdaderos moralistas?” la revista publicaba a los reconocidos dibujos de 
Disney como emisores de la "moral". Del otro lado de la cordillera Ariel Dorfman y Anmand Mattellart (2009) escribían el ya clásico análisis del mundo presentado por Disney, donde señalaron la reproducción de las nociones clásicas del patriarcado, la anulación de la mujer (presentándola como mero objeto de deseo e inútil), la valoración positiva de la masculinidad y la negación de la sexualidad infantil.

La búsqueda de relación entre la segregación sexual y las condiciones de opresión de Argentina por la cultura norteamericana era un tema demarcado en otros documentos (Simonetto, 2014). Con esto, el FLH buscaba una doble estrategia. Por un lado, señalaba que al igual que otros agentes de la izquierda, el imperialismo era uno de sus enemigos a disputar, y como tal, buscaba superar la diferencia que los demarcaba como agentes de un colectivo social que llamaron "pueblo". La imagen presenta un "ellos" (el imperialismo), en la vereda de enfrente del espectador. Por el otro, el moralismo como dispositivo de demarcación y segregación de la disidencia sexual, es asociado a una valoración negativa, ergo señalado como un elemento ajeno a la cultura de izquierda, un elemento político externo a la lógica de la liberación por la que pugnaban los sujetos con los cuales esperaban establecer un dialogo, miembros activos de otras fuerzas políticas.

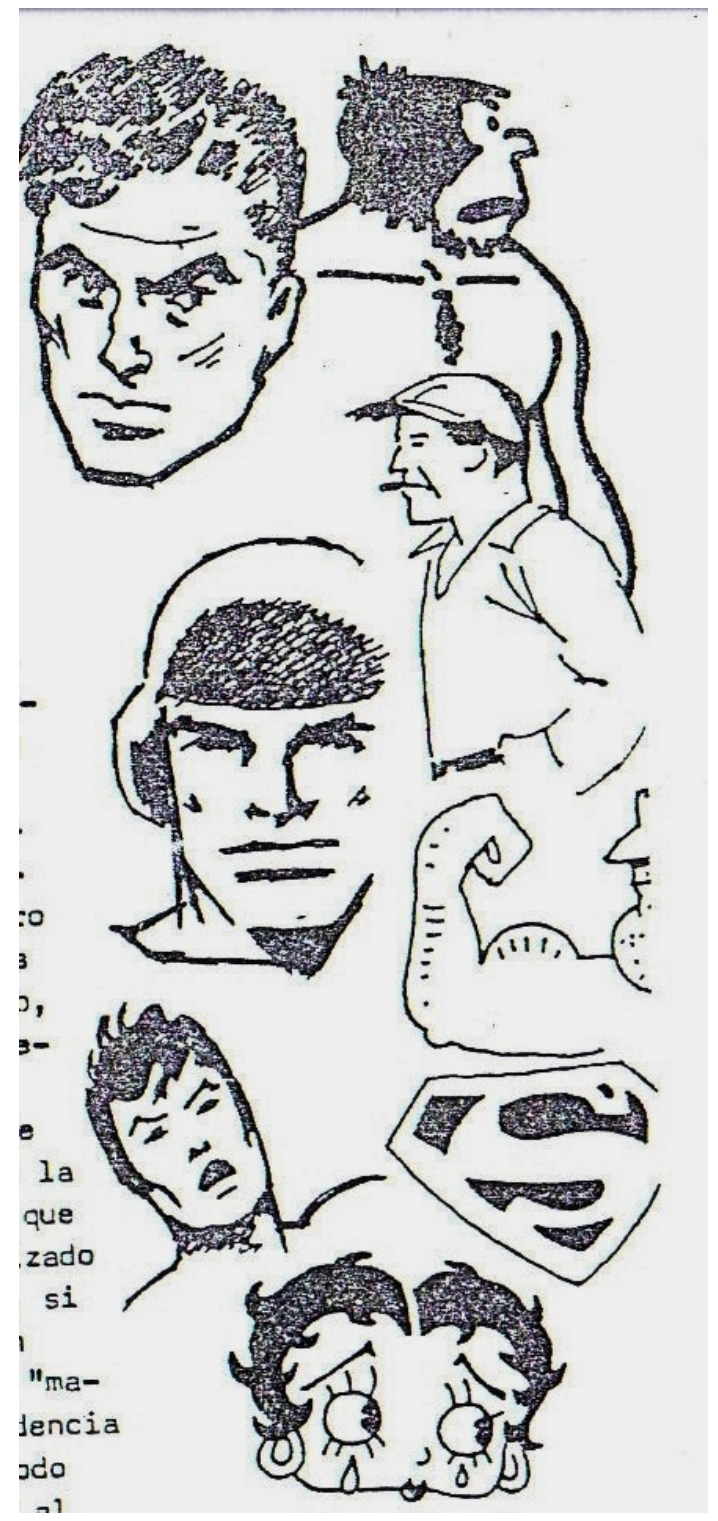


La Imagen $\mathrm{N}^{\circ} 3$ apareció en un artículo teórico de la revista, donde un autor anónimo, argumentaba sobre los modos en que lo femenino/masculino, la lógica binaria, opera en los modos de subjetivación de los sujetos, colocando por un lado al macho/"chongo" y por el otro a las mujeres y "locas". La crítica a la masculinidad como agente aliado de la lógica del capital era tal que el autor sostenía que la "loca" llegaba a ser subversiva y de ahí la molestia y la persecución a la misma, por transgredir estos "moldes".

Quizás como ejemplo de la representación que el FLH tenía de esta "masculinidad", tres cuartos de la ilustración mostraban sentidos asociados al mismo. Un orangután, una bestia dotada de fuerza e irracionalidad, que no casualmente era empleado en otras imágenes asociadas a la represión y a la policía. El gorilismo, la derecha y el "machos" aparecen como signos lindantes (Simonetto, 2014). El músculo como asociación de la fuerza, al lado de un varón que expresa indiferencia, insensibilidad. El logo de "superman" demarca la idea de un superhombre, supermacho, como imposición moral extranjera, enemiga de los desafíos expuestos por el proceso de liberación.

En el margen inferior, la imagen femenina, sufre. La imagen de un ser "emocional" que se lamenta el "peso" de los imaginarios masculinos. De este modo los autores se proponían exponer la verdadera composición de elementos mostrados como "naturales" y sus implicancias sociales, hacerlos estallar y mostrar sus consecuencias.

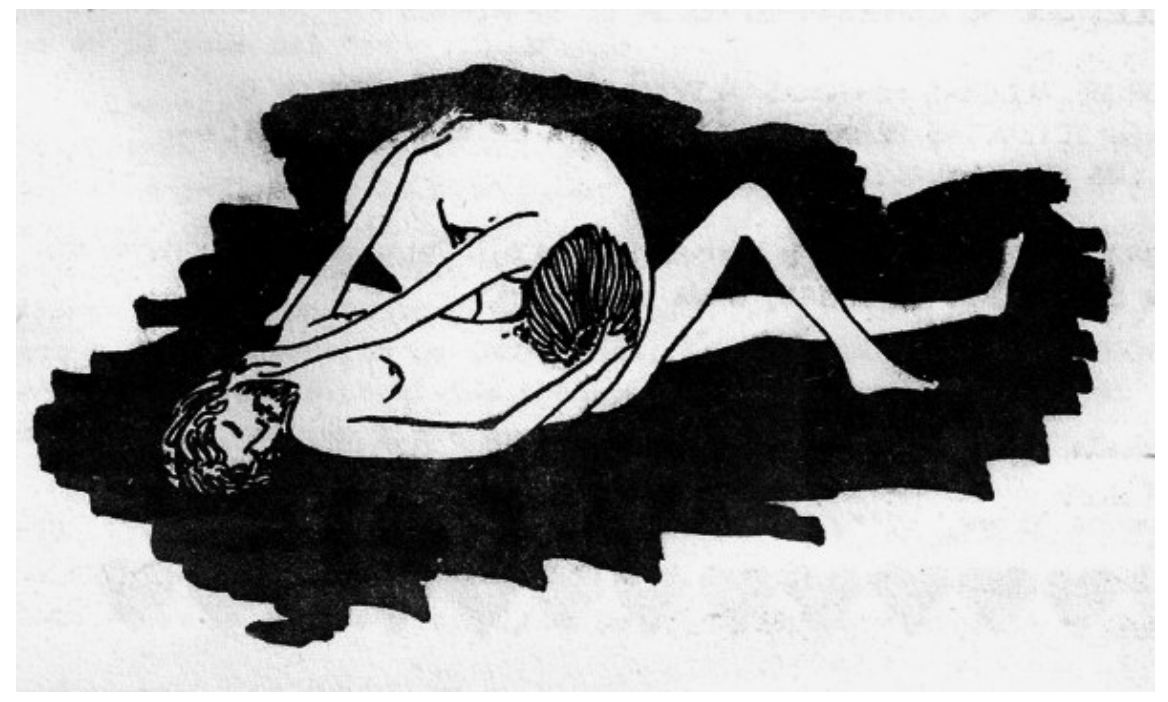

Imagen $\mathrm{N}^{\circ}$ 4, Somos $\mathrm{N}^{\circ}$ 5, 1975.

Por último, su estrategia visual no buscó solamente desarticular por vías negativas elementos cosificados en la vida social asociados a un sistema androcéntrico. A pesar de que muchos dibujos se ocuparon de la represión, quizás como reconocimiento, de un elemento clave a la hora de pensar los modos de subjetivación de la disidencia sexual, también propiciaron visibilizar las estrategias que estos sectores encontraron, las alianzas sociales y afectivas, para consolidar sus formas de existencia. Los relatos homosexuales abarcaron la denuncia y la penuria, pero también, el humor, el chiste, la anécdota, el recuerdo, la catarsis emocional: resultado modos de expandir aquellos que ellos asociaban a un proceso de concientización sobre la homosexualidad.

Lo lograran o no, con un corto alance de seguro, la Imagen $\mathrm{N}^{\circ} 4$ ilustra cómo en los estrechos márgenes sociales posibles, otras formas de placer y de empeño de la sexualidad se hacían presente, transgrediendo los límites de lo pensable/decible para la época, colocando el placer, la 
sensualidad y el deseo no solo como dominio eterno de la heterosexualidad, sino también, como puertas abiertas para otras formas de relación socio-afectivas.

\section{Femenino/Masculino en la noción Homosexual}

La noción de Género es crucial para comprender la narrativa histórica y la consolidación del modelo de nación. En palabras de Pablo Ben (2010) la consolidación del Estado Nacional no puede ser comprendida sin un análisis de las imposiciones que desde allí se realizaron para adecuar las subjetividades a un modelo representado por el varón blanco, occidental, argentino, heterosexual y de élite. A su vez, el proceso peronista operó sobre la trama relacional de género en el campo político. Al establecer la relación binaria nosotros/ellos, se construiría por un lado al pueblo viril, valiente y predispuesto, identificado con la virilidad de su líder Perón, frente a una oligarquía débil y femenina. Si para Verón y Sigal (2010) la identificación con Perón significaba la configuración de la tríada Nación-Perón-Verdad, esta a su vez era cumplimentada con la figura del macho, del líder masculino. El discurso peronista significaba una ruptura con una supuesta posición femenina que los trabajadores, contenidos en la figura de nación, habían tenido frente al capitalismo oligárquico. Por ejemplo, en el enfrentamiento que el primer gobierno peronista sostuvo con la iglesia católica, se acusaba a los curas de "Homosexuales afeminados y revoltosos", se codificaban de este modo en la política argentina valoraciones genéricas (Acha y Ben, 2004). En este sentido, creo fundamental comprender las representaciones de lo masculino y lo femenino en la revista Somos, como un indicio de las nociones establecidas en el imaginario político del FLH.

El término "homosexual" articula para dicha organización un conjunto de prácticas, como el lesbianismo, la homosexualidad masculina y el travestismo, que aunque aparecen enumeradas en la revista y en los relatos, no se encuentran diferenciadas como identidades particulares, sino más bien bajo este signo unívoco. Lo cual no significa de ningún modo que en el FLH militaran solo varones: el grupo SAFO, que era miembro del Frente, era un grupo de lesbianas. Esta dimensión, nos daría cuenta de la composición anatómica/sexual, aunque también en la representación la referencia constante a miembros masculinos como predominantes; sabiendo por ejemplo que en sus referentes se podrían encontrar a Nestor Perlongher y Hector Anabitarte, ambos varones. Como primer punto, y por lo señalado en la revista, queda claro que la voz de los varones se encuentra resaltada en una polifonía por sobre la de las mujeres.

Pero si en nuestro análisis, a su vez, desdoblamos este concepto auto referencial, es decir la reivindicación homosexual, y nos preguntamos ¿A qué se refiere exactamente con el término homosexual? ¿Se considera homosexuales a todos aquellos que sostienen prácticas disidentes con la norma heterosexual? Existe en la revista, una clara diferenciación en varios sentidos. Por empezar, sin salirse de la relación binaria, se establece una distinción entre el homosexual/chongo, pasivo/activo, penetrado/penetrador, masculino/femenino. A pesar de su recurrente crítica a la genitalización de las prácticas sexuales, en los relatos se plasma la auto percepción de una identidad definida por el rol ocupado en el acto sexual, donde el sujeto no sería definido por la práctica en sí, sino por el rol que elije o selecciona en dicha práctica. En otra dimensión, el homosexual aparecía dibujado por la demarcación punitiva ejercida desde el Estado, y en otro nivel, por la sociedad en general, por las normas expulsivas, que centralmente atacaban a quienes se referenciaban públicamente como homosexuales y por ende con la caracterización feminizada de esta identidad. Quizás por esta razón, quienes escribían en la revista Somos y se organizaban en el FLH, se vieron incapacitados para insertarse en la dimensión pública de las organizaciones políticas. Esta concepción, o aceptación del homosexual como quien liga la noción femenina a su preferencia sexual, delimita en algún sentido la figura de la homosexualidad dentro del campo femenino. 


\section{Palabras finales}

A lo largo de este escrito, hemos intentado dar cuenta del universo simbólico, de los horizontes culturales y de las constelaciones críticas propuestas por la publicación Somos del Frente de Liberación Homosexual. A partir de este análisis me gustaría señalar una serie de consideraciones a modo de conclusión.

$\mathrm{Al}$ inicio del articulo establecí un nexo de contacto entre el objeto de análisis y la actualidad: la transición de la publicación Somos al suplemento Soy. Como primer punto, cabe señalar que dicha reconfiguración de caracteres presenta la articulación de experiencias disímiles en dos instancias temporales heterogéneas, donde quizás la distancia sea la que en mayor medida complejice la lectura desde la lejanía. Somos era un fanæine de tirada reducida, un foro polifónico de expresión que respondía a un proyecto político del FLH. Su objetivo era ser un medio de organización y difusión de quienes se identificaban no solo como homosexuales, sino a su vez, como agentes de una política activa por la transformación radical de la sociedad. Por su parte Soy es un suplemento que participa de un diario de tirada masiva, Pagina 12, cuyo anclaje central se encuentra en presentar un proyecto editorial que dé cuenta de formas identitarias diversas que hoy adquirieron visibilidad social, trabajando distintas actividades que para la línea editorial del medio, constituyen fundantes del modo de vida representado.

La simple comparación de estas dos publicaciones, no en términos estrictos, sino más bien en las tendencias de sentido que estas producen, nos permite establecer o demarcar dos tiempos distintos: los cuales difícilmente podrían ser leídos el uno sin el otro. Por un lado Somos fue una de las primeras publicaciones en abarcar la temática de la disidencia sexual en nuestro país y en nuestro continente, y como tal, consistió en una de las primeras instancias organizativas de aquellos movimientos que se propusieron debilitar los discursos ético-morales hegemónicos, que como hemos señalado eran transversales al conjunto de la sociedad, atravesando variadas organizaciones políticas, espacios y campos sociales. Podemos pensar que serían posiblemente impensables gran parte de las producciones culturales actuales sin este desafió a la relación de fuerza en los años 70'. Las actividades pioneras abrieron la brecha para la visibilización de estas prácticas e intentaron poner en algunas zonas de la esfera pública la condición humana negada a gran parte de la comunidad homosexual. Por su parte, Soy representa a otro conjunto de instancias, de disputas de sentidos y de construcción de espacios desde donde elucidar críticamente y sin los cuales posiblemente no se hubiese intentado repensar desde la perspectiva de género los acontecimiento de nuestra historia reciente. De algún modo existe un lazo retroactivo entre ambas. Existe entre ambas un suerte de unidad semántica que ha transgredido las últimas décadas y que retroalimenta a cada una de ellas.

El hecho de que exista un suplemento masivo como Soy, se debe de alguna u otra manera, a que las conquistas en el campo jurídico como así también en el social, por la acción política de un linaje de organización, como así también, al debilitamiento de ciertos patrones o quizás a su reconfiguraciones, ha delimitado una distancia entre la violencia física y la simbólica, que hace posible su circulación. En la década indagada sería de seguro imposible pensar la producción masiva de un suplemento anclado en estas dimensiones identitarias. La realización de esta imposibilidad, responde a un cambio profundo en nuestra sociedad. Si durante algún tiempo podríamos pensar que lo dominante entendió a la identidad no heterosexual como un sujeto contra hegemónico a desplazar, hoy quizás estemos ante una reconfiguración del patrón de constitución de la hegemonía, que como sabemos siempre cambiante, ha insertado dentro de sus horizontes sociales de realización, de manera desigual, la posibilidad de introducción de las identidades sexuales disidentes.

Este punto nos lleva a pensar en una segunda instancia: la que comprende el cambio enunciativo de Somos, como un plural, al activo singular de Soy. Ha habido, como producto de distintas transformaciones políticas, un cambio profundo en la episteme de las organizaciones, revistas y 
espacios que centran su actividad en las diferencias producidas por los patrones jerarquizados del género. Mientras que en la década indagada la constante que atravesaba el horizonte de la organización era la subversión político-estructural de la sociedad de clases, donde el proceso de organización entablaba como principal objetivo no solo desarticular las estructuras patriarcales, sino a su vez lograr la liberación de toda instancia de dominación, hoy la singularidad de este enunciado nos habla de una lógica totalmente distinta. Hemos asistido de algún modo a la exaltación de la política anclada en la identidad: mientras Somos reducía la diferencia a la figura única de la homosexualidad, Soy busca dar cuenta de decenas de identidades que se prefiguran disidentes de los patrones binarios. Por un lado se ha abandonado la invisibilidad de otros actores que en Somos aparecían solo como homosexuales. Pero este paso ha colocado el foco central en la constitución de la identidad propia en relación al otro, por ejemplo ante el estado como ciudadanos, perdiendo así la pulsión originaria de subversión radical del nodo, o reconfigurándola en otra topografía de la dimensión política. Plantearse hoy la realización individual de un Soy da cuenta de que se han movido los marcos que delimitaban hegemónicamente los horizontes simbólicos donde los agentes tenían la posibilidad de definirse, pero a su vez ¿No es plausible pensar que este desplazamiento de los límites demarque uno nuevo? ¿Será factible esgrimir que esta emergencia de identidades anunciadas solas en una configuración singular sean partícipes de la hegemonía de modelos dominantes? ¿Han perdido estos modelos su carácter estructurarte de género o asimismo los patrones de acumulación económicos que eran denunciados desde la pluralidad de Somos?

Existen numerosas instancias que deben convocarnos a la reflexión crítica. El trabajo sobre Somos resulta llamativo en cuanto a que sus numerosas estrategias discursivas, humorísticas, semióticas, a través de las cuales, por medio de la destrucción y la producción de sentidos la publicación se planteó disputar una serie de signos. Se propusieron deslindar la valoración negativa asociada a la homosexualidad, estableciendo nuevas interconexiones significantes, que permitieran comprender de otro modo la dignidad de ser de un colectivo social, que por sus distintas prácticas, estaba constantemente condenado a no ser nada, o en otro sentido, a solo ser negativo. Su misma nominación de ser un sujeto colectivo, Somos, con diversidad de historias, pero con una preocupación común, establecía ya un claro sentido, el de establecerse como espacio de organización y lucha para "vencer y conquistar la dignidad humana que se nos niega."3.

Existen relaciones diversas entre las dos temporalidades señaladas y para concluir, yo he decido recortar una parte o sintetizar un conjunto de procesos históricos complejos que atraviesan la historia social y que nos traen al presente tanto de nuestro país como del mundo. Lo que persiste nítidamente en el proyecto editorial enarbolado por el FLH es la necesidad de elucidar los procesos por los cuales siguen tramando y operando los dispositivos ético-morales, no solo sobre la lectura histórica que se realiza a la lejanía, sino también sobre el mundo cercano que se cierne de entre nosotros. Lo que aparece como una constante en la producción del itinerario de Somos es aquello que señaló Benjamin en una de las variables de sus famosas tesis: "Función de la utopía revolucionaria: iluminar la zona de lo que merece ser destruido” (Díaz, 2009).

\section{Bibliografía}

AA.VV. (2013) Perder la forma bumana, Museo Nacional, Centro de Arte Reina Sofia, España.

Acha, Omar y Ben, Pablo (2004) Amorales, patoteros, chongos y pitucos. La homosexualidad masculina durante el primer peronismo (Buenos Aires, 1943-1955). [En línea] Trabajos y Comunicaciones, 30 31.

${ }^{3}$ El fascismo nos amenaza. Comunicado público del FLH. Archivo de la CHA. 
Ben, Pablo (1997) Las relaciones sexuales entre personas del mismo sexo y el origen bistórico de la homosexualidad, en Razón y Revolución $\mathrm{N}^{\circ}$ 3, edición electrónica.

Benjamin, Walter (2007) Conceptos de Filosofía de la Historia, Terramar, La Plata/ Buenos Aires.

---on (2012) El París de Baudelaire, Eterna Cadencia, Buenos Aires.

Biernat, Carolina (2007), "Médicos, especialistas, políticos y funcionarios en la organización centralizada de la profilaxis de las enfermedades venéreas en la Argentina (1930-1954)", en Anuario de Estudios Americanos, Sevilla, vol. 64, nº $1 .$.

Bilbao, Bárbara (2012) Frente de Liberación Homosexual (1971-1976): Prácticas comunicacionales de resistencia y re significaciones en la bistoria de la Argentina reciente, en Question $\mathrm{N}^{\circ} 31$.

Diana, Marta (1996) Mujeres guerrilleras, Planeta, Buenos Aires.

Díaz, Ariane (2009) "Dialéctica e Historia. El marxismo de Walter Benjamin", en Lucha de Clases $\mathrm{N}^{\circ}$ 8. Buenos Aires.

Dorfman, Ariel y Matterlart, Armand (2009) Para leer al Pato Donald. Comunicación de masas y colonialismo, Siglo XXI, Buenos Aires.

Eagleton, Terry (2001) Una idea de cultura. Una noción politica de los conflictos culturales, Paidós, Buenos Aires.

Eagleton, Terry (2013) Marxismo y crítica literaria, Paidós, Buenos Aires.

Felliti, Karina; Cosse, Isabella, Manzano, Adriana Valeria (2010) Los 60'de otra manera: vida cotidiana, género y sexualidad de la Argentina, Prometeo, Buenos Aires.

Godelier, Maurice (2005) La producción de grandes hombres. Poder y dominación masculina entre los Baruya de Nueva Guinea, Madrid, Akal.

Grammático, Karin (2007) "Las mujeres políticas y las feministas en los tempranos años setenta. ¿Un dialogo (im)posible?”, en Historia, género y política en los '70, Buenos Aires, Feminaria.

Grüner, Eduardo (2010) La oscuridad y las luces. Capitalismo, cultura y revolución, Edhasa, Buenos Aires.

Halperin, Paula y Acha, Omar, comps. (2000), Cuerpos, Géneros e Identidades. Estudios de Historia de Género en Argentina, Ediciones del Signo, Buenos Aires.

Insausti, Santiago (2007) Una mirada sobre la publicación del Frente de Liberación Homosexual, IV Jornadas de Historia de las Izquierdas.

Insausti, Santiago (2012) "Selva, plumas y desconche: Un análisis de las performances masculinas de la feminidad entre las locas del Tigre durante la década del ochenta", en Revista Latinoamericana de Estudios sobre Cuerpos, Emociones y Sociedad RELACES N ${ }^{\circ}$ 7, Córdoba.

Izaguirre, Inés, comp. (2012) Lucha de clases, guerra civil y genocidio en la Argentina. 1973-1983, EUDEBA, Buenos Aires.

James, Daniel. (comp.). (2003) Violencia, proscripción y autoritarismo (1955-1976), Editorial Sudamericana, Buenos Aires.

Marcuse, Hebert (1984) Eros y civilización, Sudamericana / Planeta, Barcelona.

Maristany, José (2010) Dicen que aqui no podemos hacerlo, Editorial Biblos, Buenos Aires.

Oberti, Alejandra (2013) "Las mujeres en la política revolucionaria: el caso del PRT-ERP en la Argentina de los '70", Interthesis, 1.

Peller, M. (2012) "Experiencias de la herencia. La militancia armada de los setenta en las voces de la generación de las hijas y los hijos", en Revista Afuera, 12.

Perlongher, Néstor (2008) Prosa Plebeya, Colihue, Buenos Aires.

Pucciarelli, Alfredo (1999) La primacía de la política. Lanusse, Perón y la Nueva Izquierda en tiempos del GAN, EUDEBA, Buenos Aires.

Puig, Manuel (2010) El beso de la mujer araña, De Bolsillo, Buenos Aires.

Schneider, Alejandro (2005) Los compañeros. Trabajadores, Izquierda y Peronismo 1955-1973, Imago Mundi, Buenos Aires.

(2013) "Una lectura sobre las organizaciones de base del movimiento obrero argentina (1955-1973)", en Arcbivos de bistoria del movimiento obrero y la izquierda $\mathrm{N}^{\circ} 2$. 
Schultze, Fernando Rada (2012). Una aproximación a las demandas y estrategias del movimiento Lésbico Gay Argentino en el periodo 1967-1976, Segundo congreso interdisciplinario de género, Córdoba.

Sebreli, Juan José (1997). "Historia secreta de los homosexuales en Buenos Aires", en Escritos sobre escritos, cindades bajo ciudades 1950-1997, Buenos Aires, Sudamericana.

Sepúlveda, Patricia (2013) Género, memoria y militancia en la década de 1970, Tesis de Maestría. Defensa pública 22 de Julio.

Simonetto, Patricio (2014) "Imagen, estética y producción de sentido del Frente de Liberación Homosexual (1967-1976)", en Corpus [En línea], Vol 4, No 1.

Simonetto, Patricio (2014) "Los fundamentos de la revolución sexual: teoría y política del Frente de Liberación Homosexual (1967-1976)", en Anuario de la Escuela de Historia Virtual Vol. 6, N ${ }^{\circ}$ 6, Córdoba.

Trebisacce, C. (2010) "Una segunda lectura de las feministas en los años '70 en la Argentina”, en Conflicto Social, 4.

Trebisacce, C. (2013) "Un fantasma recorre la izquierda nacional. El feminismo de la segunda ola y la lucha política en la Argentina de los setenta", en Sociedad y Economía, 24.

Verón, Eliseo y Sigal, Silvia (2010) Perón o muerte. Los fundamentos discursivos del fenómeno peronista. EUDEBA, Buenos Aires.

Vespucci, G. (2011) "Explorando una tríada conceptual: homosexualidad, familia y liberación en el discurso del Frente de Liberación Homosexual”, en Historia Crítica, 43.

Vezzetti, Hugo (1985) La locura en Argentina, Paidós, Buenos Aires.

Voloshinov, Valentín Nikoláeivich (2009) Marxismo y filosofía del Lenguaje, Ediciones Godot, Buenos Aires.

Wasem, Marcos (2008) Barrocoso y sublime, poética para Perlongher, Ediciones Godot, Buenos Aires.

Williams, Raymond. (2009), Marxismo y Literatura, La Cuarenta, Buenos Aires.

Wilson, Colin (2011) "Queer theory and politics", en Socialist Journal No 132.

\section{Documentos}

Diario Clarín, 9 de febrero y 3 de marzo de 2013.

Revista Somos, $\mathrm{N}^{\circ} 1$ al 8. Archivo CHA.

Suplemento Soy, Diario Página/ 12, 28 de marzo de 2008. 